\title{
Lymphocytes B et T ont un ancêtre commun: identification in vitro d'une cellule souche lymphoïde
}

Personne ne conteste plus, depuis les expériences de reconstitution in vivo avec des cellules individuelles, ou avec des cellules ayant intégré un marqueur clonal, qu'une seule cellule puisse reconstituer toutes les lignées hématopoiétiques, et cela à long terme [1]. On sait aussi qu'au cours de ses divisions initiales, une cellule souche restreint progressivement son potentiel de différenciation. En revanche, on dispose de très peu de données sur l'ordre dans lequel se fait cette restriction, si elle implique l'individualisation précoce d'une cellule souche lymphoïde dépourvue de potentiel myéloïde, et si cette hiérarchie est immuable ou susceptible de régulation par des signaux extrinsèques. Kondo et al. (Stanford, CA, USA) démontrent dans un article récent de Cell la réalité d'une cellule souche lymphoïde commune aux lignées B, T et NK incapable de différenciation myéloïde [2]. Une telle dissection de la hiérarchie hématopoïétique se heurte à deux obstacles : (1) il faut pouvoir suivre le destin de cellules individuelles; (2) les conditions requises pour la différenciation $\mathrm{T}$ sont très spécifiques (environnement thymique) et peuvent être incompatibles avec celles requises pour le développement B ou myéloïde. Pour surmonter ces difficultés, les auteurs ont procédé par étapes, individualisant d'abord sur des critères phénotypiques et, en particulier, sur l'expression de la chaine $\alpha$ du récepteur de l'interleukine-7, une population qui fonctionnellement in vitro comme in vivo peut engendrer toutes les lignées lymphoïdes (B, T et NK) mais est incapable de différenciation dans les lignées myéloïdes. Cette population, rare $(0,02 \%$ des cellules médullaires) se distingue par son profil antigénique (c-kit ${ }^{+}, \mathrm{Sca}^{+}{ }^{+}$, Thy-1.1-Lin'-, exprimant la chaîne $\alpha$ souches myélo-lymphoïdes, mais aussi des précurseurs pro-thymocytes et pro-B. La fréquence dans cette population de progéniteurs lymphocytaires T est de 1/20 et la fréquence des progéniteurs $B$ est la même. La co-habitation de progéniteurs restreints à la lignée $\mathrm{T}$ ou $\mathrm{B}$ pouvant expliquer ce résultat, encore fallait-il prouver que certaines de ces cellules, prises isolément, possédaient les deux potentiels. Compte tenu de l'incompatibilité des systèmes de culture, la seule possibilité était d'induire les divisions d'une cellule (c-kit ${ }^{+}$, Sca-1 ${ }^{+}$, Thy-1.1-, $\mathrm{Lin}^{-}, \mathrm{IL}^{-7}-\mathrm{R}^{+}$) dans des conditions ne compromettant pas l'expression ultérieure des potentialités $\mathrm{B}$ et $\mathrm{T}$, puis de micro-injecter une partie des cellules filles dans des lobes thymiques et de cultiver les autres dans des conditions favorisant leur différenciation en lymphocytes B (co-culture en présence de cellules stromales compétentes). Sept des 20 cellules initiales ainsi testées ont produit des lymphocytes $\mathrm{B}$ et $\mathrm{T}$, prouvant ainsi la double potentialité de la cellule parentale. On peut donc affirmer maintenant qu'existe dans la hiérarchie hématopoiétique une population de cellules souches de potentiel exclusivement lymphoïde et incapable de différenciation dans les lignées myéloïdes. On peut sans grand risque faire l'hypothèse que cette même hiérarchie existe chez l'homme ce qui était déjà fortement suggéré par les travaux de A. Galy en 1995 identifiant chez l'homme une fraction CD $34^{+}{ }^{-}$hyy $1^{-} \mathrm{CD} 45 \mathrm{RA}^{+}$ $\mathrm{CD} 10^{+}$de cellules médullaires adultes douée de potentiel $\mathrm{B}$, NK et dendritique et dépourvue de potentiel myéloïde [3]. Qu'une même cellule exprime simultanément les potentiels $B$ et T n'avait toutefois pas été directement confirmé. Rien ne prouve cependant, que ce soit chez l'homme ou la souris, que ces cellules souches lymphoïdes soient une étape obligatoire lors de la détermination des cellules souches totipotentes vers les différentes voies lymphoïdes. Il ne faut pas perdre de vue non plus que le schéma de la hiérarchie hématopoiétique, tel qu'il nous est proposé, est construit à partir d'observations faites dans des systèmes biologiques dont les limites et le côté artificiel ne doivent pas être sous-estimés. La question est maintenant de caractériser les verrous moléculaires associés à cette restriction du potentiel des cellules souches et de prouver s'ils sont irréversibles.

L.C.

1. Coulombel L, Vainchenker W. Les cellules souches hématopoïétiques. Med Sci 1995; 11 : 13-6. 2. Kondo M, Weissman IL, Akashi K. Identification of clonogenic common lymphoid progenitors in mouse bone marrow. Cell 1997; 91 : 661-72. 3. Galy A, Travis M, Cen D, Chen B. Human T, B, natural killer and dendritic cells arise from a common bone marrow progenitor subset. Immmunity $1995 ; 3: 459-73$.

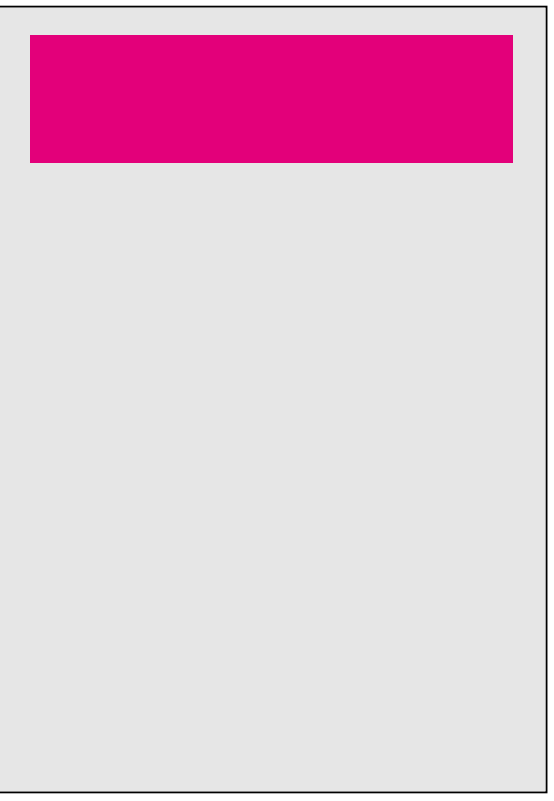

$\mathrm{m} / \mathrm{s} n^{\circ} 5$, vol. 14 , mai 98 